\title{
KETERPENJARAAN TOKOH PEREMPUAN \\ DALAM CERPEN THE YELLOW WALLPAPER KARYA CHARLOTTE PERKINS GILMAN
}

\author{
Oleh : \\ Ratna Asmarani \\ Email: ratna_asmarani@yahoo.com \\ Fakultas Ilmu Budaya UNDIP \\ Jl. Prof. Soedarto SH, Tembalang Semarang
}

\begin{abstract}
The purpose of this paper is to analyse the problems around the imprisonment of the female protagonist in Chalotte Perkins Gilman's short story entiled The Yellow Wallpaper. The focus of the analysis is on the actors and factors causing imprisonment, types dan impacts of imprisonment, efforts to overcome the imprisonment, and the end of the imprisonment experienced by the female protagonist. To analyse this problems, feminist literary criticism is used supported by the stereotypes of the nineteenth century women, the medical opinion at that time and the feminist perspective concerning the mental disorder experienced by women, and the concept of oppression in the imprisonment as well. The result shows that a woman who experiences the physical and psychological imprisonment in the patriarchal household area tends to have mental disorder as an alternative to gain freedom. The conclusion that can be drawn is that in the patriarchal environment women's movement area and psychological, emotional, intellectual actualization tend to be limited in which the women who fight against those linitations will get the stigma of suffering from mental illness.
\end{abstract}

Key words : imprisonment, feminist literary criticism, mental disorder, oppression.

\section{PENDAHULUAN}

Cerpen berjudul The Yellow Wallpaper karya Charlotte Perkins Gilman yang diterbitkan tahun 1892 bercerita tentang seorang perempuan, istri seorang dokter, yang menderita depresi setelah melahirkan anak keduanya. Sesuai dengan tindakan medis saat itu, sang suami membawa istri ke tempat peristirahatan agar istrinya bisa beristirahat secara total, namun si istri merasa terpenjara secara fisik, psikis, emosional dan intelektual. Dalam kondisi tertekan karena terus menerus berada dalam kamar di lantai atas, si istri yang pada dasarnya sangat imajinatif dan kreatif mulai memusatkan perhatiannya pada wallpaper di kamarnya.
Ia mengidentifikasi adanya sosok perempuan imajiner yang terperangkap dalam pola gambar wallpaper dan merasa senasib. Tingkah laku istri di akhir cerita membuat suaminya yang seorang dokter mendadak jatuh pingsan. Berdasarkan fokus cerita, sangatlah relevan untuk menganalisis keterpenjaraan tokoh utama perempuan dalam cerpen karya Gilman tersebut.

\section{LANDASAN TEORI}

Untuk mengkaji permasalahan keterpenjaraan tokoh perempuan dalam cerpen Gilman digunakan kerangka kritik feminisme yang intinya menyoroti permasalahan paradigma tradisional 
HUMANIKA Vol. 21 No. 1 (2015) ISSN 1412-9418

Keterpenjaraan Tokoh Perempuan Dalam Cerpen

The Yellow Wallpaper Karya Charlotte Perkins Gilman

Ratna Asmarani

tentang perempuan atau peran sosial yang ada dalam karya sastra dari perspektif perempuan. Kutipan berikut mendukung pernyataan di atas: "Feminist criticism reads writing and examines its ideology and culture with a woman-centred perspective. Criticism is feminist if it critiques existing disciplines, traditional paradigms about women, nature or social roles, or documents such as work by others, from the point of view of women" (Humm, 1995: 51).

Sementara itu, keterpenjaraan adalah suatu situasi di mana seseorang, dalam analisis ini adalah seorang perempuan, berada dalam kondisi seperti di dalam penjara, yaitu terbatasi minimal secara fisikal. Makna kamus dari keterpenjaraan adalah sebagai berikut: "Imprisoment is: 1. putting someone in prison or in jail as lawful punishment; 2. the state of being imprisoned; 3. the act of confining someone in a prison (or as if in a prison)"

(http://www.audioenglish.org/dictionary/i mprisonment.

htm diakses 5 Januari 2013).

Kondisi terpenjara, fisik maupun psikis, tak terelakkan lagi menimbulkan suatu kondisi teropresi yang bisa bersifat publik atau privat dan individual: "Oppression can be experienced publicly or privately, does not exist naturally and may be directed to an individual or a collective group" (http://www.socialdimension.com/2011/10/understandingoppression-in-mental-health.html diakses 1 Januari 2014). Opresi juga bisa bersifat beban mental atau psikologis: "Oppression ... can also mean to mentally burden someone, such as with the psychological weight of an oppressive idea" (http://womenshistory.about.com/od/femini sm/a/oppression.htm diakses 1 Januari 2014). Opresi juga bisa berbentuk opresi sosial misalnya dalam bentuk sistem kesehatan mental yang berkaitan dengan orang-orang yang tingkah lakunya dinilai menyimpang: "Social oppression is observable in the mental health system, which deals with people whose behaviour deviates from the normative social and cultural expectations of the society" (http://www.social-dimension.

com/2011/10/understanding-oppression-inmental-health.html diakses 1 Januari 2014).

Seseorang, dalam analisis ini adalah tokoh perempuan, yang tingkah lakunya dinilai tidak berterima secara sosial dan kultural, sering mendapat stigma tidak sehat secara mental/psikis. Dengan kata lain perempuan-perempuan yang seperti itu sering dianggap mengalami kegilaan. Secara medis, dokter dianggap paling berhak untuk memberikan penilaian, namun feminis menyangsikan hal tersebut: "Doctors are seen as the leaders of the mental health team, largely due to their professional standing in the medical field. But do they necessarily know the best?" (http://www.social-

dimension.com/2011/10/understandingoppression-in-mental-health.html diakses 1 Januari 2014).

Keberatan kaum feminis ini dilandaskan pada dua hal. Yang pertama karena tindakan medis yang umumnya dilakukan terfokus pada tubuh. Tubuh yang tidak berfungsi dengan baik dianggap sebagai penyebab gangguan mental "The theoretical point of view of this mechanistic medical model of mental illness is that, somatic, or aberrant bodily process are the cause of mental disorders" (http://louiseelcross.hub

pages.com/hub/Women-and-

depression-through-the-ages-Part-three diakses 2 Januari 2014).

Keberatan kedua adalah tentang faktor penyebab tidak sehatnya mental/psikis perempuan. Kaum feminis melihat bahwa ketidaksehatan mental seorang perempuan lebih bersifat sistemik di mana faktor-faktor sosial mengopresi dimensi kehidupan perempuan: "By 
rooting mental health issues in the body and treating individual symptoms, we do not look at the external social factors that are also impacting how an individual is thinking, acting and feeling" (http://www.shamelessmag.com/blog/2012 /08/guest-post-the-psychologicalispolitical-mental-/diakses 1 Januari 2014).

Bagi kaum feminis posisi perempuan dalam masyarakat yang tidak memiliki kuasa apapun menjadi penyebab utama: "it is women's position in society that drives them $\operatorname{mad} . .$. , madness or depression in women is in reality the cry of the powerless and the aim of psychiatry, is, and has been, to silence that cry and keep social order" (http://louiseelcross.hubpages.com/hub/Wo men-and-depression-through-the-agesPart-three diakses 2 Januari 2014).

Kaum feminis berpendapat bahwa kegilaan adalah suatu bentuk jeritan ketidakberdayaan perempuan. Pembungkaman atas jeritan ini, melalui tindakan medis yang legal, disinyalir sebagai suatu tindakan untuk menciptakan keteraturan sosial yang dijunjung tinggi dalam dunia patriarkis.

Hal ini senada dengan yang dikemukakan Chesler, yaitu bahwa 'kegilaan' yang dialami perempuan adalah akibat tidak dihargainya peran perempuan atau sebagai bentuk penolakan stereotip peran perempuan: "Phyllis Chesler, in her pioneering work Women and Madness (1972), argues that 'madness' is a label used for people whose behavior radically depart from what is socially prescribed. What we consider madness, she suggests, is either the acting out of the devalued female role or the total or partial rejection of one's sex role stereotype" (dalam Humm, 1995: 157). Dengan demikian, di mata feminis kegilaan yang dialami perempuan samaa sekali tidak ada kaitannya dengan permasalahan fisik.

Dampak bagi perempuan yang sudah terstigmakan mengalami gangguan kesehatan mental adalah adanya 'selfstigma' di mana perempuan tersebut mendiskriminasi diri sendiri karena merasa tidak sempurna seperti yang lain: "Persons with mental health problems may also experience self-stigma, which involves discrimination of self and seeing oneself as less perfect as compared to the collective group" (http://www.socialdimension.com/2011/10/understandingoppression-in-mental-health.html diakses 1 Januari 2014).

Di sisi lain, Gilbert dan Gubar menyatakan bahwa tokoh-tokoh perempuan 'gila' dalam karya sastra yang ditulis oleh perempuan mengindikasikan empati atau perasaan senasib yang berbalut kecemasan dan kemarahan: “... is usually in some sense the author's double, an image of her own anxiety and rage" (Gilbert and Gubar, 1979: 77-78). Dengan kata lain, ada keterlibatan pandangan maupun pengalaman pribadi pengarang perempuan terhadap penciptaan tokohtokoh perempuan 'gila' dalam karyakaryanya.

Dalam masyarakat abad sembilan belas, stereotip peran perempuan cenderung bersifat lemah, pasif, penurut, bergantung, domestik, tidak logis, emosional, rentan kegilaan atau histeria, dan lain-lain yang menunjukkan kemarjinalan posisi dalam hal intelektualitas, psikis, emosional, dan seksual: "weak; passive; timid; domestic; illogical; emotional, susceptible to madness, hysteria; social/familial; dependent; unable to resist temptation; pure; content; not sexual/sensual; sphere: private"

(http://www2.ivcc.edu/gen2002/women_in _the_nineteenth_century.htm diakses 5 Januari 2014).

Apapun stereotip negatif dan marjinal tentang perempuan, dua baris terakhir puisi E. Jenning yang berjudul "The Interrogator" menunjukkan dengan 
HUMANIKA Vol. 21 No. 1 (2015) ISSN 1412-9418

Keterpenjaraan Tokoh Perempuan Dalam Cerpen

The Yellow Wallpaper Karya Charlotte Perkins Gilman

Ratna Asmarani

tepat penyebab segala masalah, fisik maupun psikis, yang dialami perempuan:

He always knows best

Male power is the key

(dalam Halliday, 2005: 40, http://vc.bridgew.edu/cgi/viewcontent.cgi? article $=1516 \&$ context $=$ jiws diakses 2 Januari 2014). Laki-laki yang selalu merasa paling tahu dan memiliki jaringan bernama patriarki ada di balik semua permasalahan yang harus dihadapi perempuan.

Penelitian sastra yang dilakukan terhadap cerita pendek karya Charlotte Perkins Gilman yang berjudul The Yellow Wallpaper menggunakan metode analisis kontekstual yang menggabungkan analisis unsur-unsur teks dengan unsur-unsur yang relevan di luar teks: "simply an analysis of a text ... that helps us to assess that text within the context of its historical and cultural setting, but also in terms of its textuality - or the qualities that characterize the text as a text" (http://www.unl.edu/english/sbehrendt/Stu dyQuestions/ContextualAnalysis.htmldiaks es 17 Februari 2014).

Kritik sastra feminis yang digunakan sebagai kerangka analisis didukung dengan pandangan feminis tentang gangguan mental terhadap perempuan dan stereotip perempuan abad sembilan belas. Selain itu, pendapat dan tidakan medis atas masalah kegilaan, konsep opresi dan keterpenjaraan juga digunakan untuk memperjelas analisis tentang masalah yang melibas tokoh perempuan yang membuatnya mengalami keterpenjaraan.

\section{PELAKU DAN FAKTOR PENYEBAB KETERPENJARAAN}

Ada pihak-pihak tertentu yang secara langsung maupun tidak menjadi penyebab keterpenjaraan yang dialami tokoh perempuan dalam cerpen Gilman. Yang bisa dikategorikan sebagai pelaku langsung adalah suami tokoh perempuan itu sendiri, seorang dokter terkenal yang mendeteksi adanya semacam depresi/histeria yang dialami tokoh perempuan tersebut setelah melahirkan anak kedua: "If a physician of high standing, and one's own husband, assures friends and relatives that there is really nothing the matter with one but temporary nervous depression-a slight hysterical tendency - what is one to do?" (Gilman, 1977: 44). Sesuai dengan standar perawatan medis saat itu, suami langsung menerapkan teknik "rest cure" 1 yang menghendaki istirahat total sekitar 2-3 bulan bagi pasien.

Pelaku tidak langsung yang mendukung keterpenjaraan tokoh perempuan adalah kakak lelaki istri yang sepemikiran dengan suami karena memiliki profesi yang sama: "My brother is also a physician, and also of high standing, and he says the same thing" (Gilman, 1977: 44). Dengan demikian seperti yang sudah dijelaskan dalam landasan teori, dokter dianggap memiliki otoritas penuh untuk mendiagnose dan menentukan teknik perawatan. Pendapat dua lelaki yang

\footnotetext{
1 The rest cure was a treatment for what was deemed hysteria in women. It had great popularity in the 19th century as a way to treat women with mental illnesses that might later be termed generalized anxiety disorder or major depression. It might also be applied to women of the upper classes who were simply exhausted by the chores of raising children, overseeing large households, or who were suffering postpartum depression after the birth of a child.
}

Dr. Silas Weir Mitchell developed the rest cure. He essentially imprisoned women for up to two months, and gave them little contact with the outside world. In the first few weeks, women were not allowed engage their minds by reading or performing small activities. Most were even not allowed to roll over in their beds, suggesting that they may have been restrained (http://www.wisegeek.com/what-is-a-restcure.htm\#slideshow diakses 5 Januari 2014) 
berprofesi sebagai dokter ini didukung penuh oleh saudara perempuan suami yang kemudian mengambil alih urusan rumah tangga (Gilman, 1977: 48) dan masyarakat umum yang tidak menentang sama sekali teknik "rest cure" tersebut.

Faktor yang sangat mendasar yang menyebabkan terjadinya depresi/hysteria pada tokoh perempuan ini adalah perbedaan karakter yang tajam antara suami dan istri. Suami tokoh perempuan adalah dokter yang "practical in the extreme" (Gilman, 1977: 43), sedangkan istri memiliki daya kreatif-imajinatif yang sangat kuat: "I used to lie awake as a child and get more entertainment and terror out of blank walls and plain furniture than most children could find in a toy store" (Gilman, 1977: 48). Meskipun sifat imajinatif mendominasi istri namun ia tetap memiliki sifat kritis seperti tampak dalam pemikirannya tentang rumah peristirahatan yang disewa suaminya untuk keperluan "rest cure" nya: "..., why should it be let so cheaply? And why have stood so long untenanted?" (Gilman, 1977: 43). Perbedaan karakter ini dipertajam dengan lingkungan patriarkis di dalam dan di luar rumah tangga yang menempatkan laki-laki sebagai pengambil keputusan yang tidak perlu mempertimbangkan pendapat maupun usulan perempuan.

\section{BENTUK KETERPENJARAAN}

Bentuk keterpenjaraan yang dialami tokoh perempuan bisa diklasifikasikan sebagai keterpenjaraan fisik dan psikis. Pengasingan ke rumah peristirahatan di daerah terpencil adalah bentuk keterpenjaraan fisik yang langsung dialami tokoh perempuan. Sejak melihat rumah peristirahatan itu, tokoh perempuan sudah memberikan penilaian negatif: "A colonial mansion, a hereditary estate, I would say a haunted house ...." (Gilman, 1977: 43). Keadaan sekitar rumah peristirahatan tersebut menguatkan kesan seperti penjara karena di kelilingi tembok dan pagar yang dilengkapi dengan gembok: "there are hedges and walls and gates that lock" (Gilman, 1977: 44).

Ruangan yang dipilih suami sebagai ruang tidur bagi istri dari sisi medis sangat lapang dan sehat, namun memberikan kesan seperti penjara. Selain terletak di lantai atas (Gilman, 1977: 45), ruangan luas itu jendelanya berjeruji, dan ornamen di dinding memberikan kesan seram seperti ornamen penyiksaan di ruang penjara kuno: "It is a big, airy room, the whole floor nearly, with windows that look all ways, and air and sunshine galore. It was a nursery first and then playroom and gymnasium, I should judge; for the windows are barred for little children, and there are rings and things in the walls" (Gilman, 1977: 45). Keadaan ini mengingatkan pada dongeng anak-anak tentang putri yang tidak berdaya dan terpenjara di puncak menara yang hanya bisa menatap keluar jendela.

Di ruangan tersebut tokoh perempuan yang menjalani "rest cure" dibatasi aktivitasnya dan dibebaskan dari segala urusan rumah tangga: "am absolutely forbidden to "work" until I am well again" (Gilman, 1977: 44). Ada perawat yang mengurusi bayinya, dan ada saudara perempuan suami yang dengan senang hati mengurusi rumah tangga dan melayani kebutuhannya (Gilman, 1977: 48). Tokoh perempuan juga tidak diijinkan untuk bertemu dengan siapapun termasuk kerabatnya sendiri (Gilman, 1977: 51). Dengan kata lain, tokoh perempuan dibebaskan dari peran gender tradisionalnya dan dibatasi sosialisasinya sehingga ia menjadi sosok yang terisolasi dari kehidupan rumah tangga dan sosial.

Selain memberikan obat yang harus diminum secara teratur, suami juga memberikan perhatian berlebih yang membuat tokoh perempan merasa terbebani secara psikis: "I have a schedule prescription for each hour in the day; he takes all care from me, and so I feel basely 
HUMANIKA Vol. 21 No. 1 (2015) ISSN 1412-9418

Keterpenjaraan Tokoh Perempuan Dalam Cerpen

The Yellow Wallpaper Karya Charlotte Perkins Gilman

Ratna Asmarani

ungrateful not to value it more" (Gilman, 1977: 45). Oleh suami, tokoh perempuan dianggap sebegitu lemah sehingga harus mendapatkan bantuan setiap saat: "And dear John gathered me up in his arms, and just carried me upstairs and laid me on the bed, and sat by me and read to me till it tired my head" (Gilman, 1977: 51). Kondisi ini memposisikan tokoh perempuan sebagai seorang invalid yang tidak bisa mengurus diri sendiri.

Keterpenjaraan secara psikis terjadi ketika suami berlandaskan alasan medis dengan tegas melarang istri berimajinasi:

I always fancy I see people walking in these numerous paths and arbors, but John has cautioned me not to give way to fancy in the least. He says with my imaginative power and habit of story-making, a nervous weakness like mine is sure lead to all manner of excited fancies, and that I ought to use my will and good sense to check the tendency. So I try" (Gilman, 1977: 47).

Menurut suami yang seorang dokter terkenal, imajinasi hanya memperparah kondisi depresi yang sedang dialaminya. Tokoh perempuan mau tidak mau terpaksa mematuhi argumen suami tersebut.

Selain dilarang berimajinasi, tokoh perempuan juga dilarang suami melakukan hobi menulisnya: "he hates to have me write a word" (Gilman, 1977: 46). Hal ini merupakan pemasungan intelektualitas dan imajinasi. Menurut suami, tokoh perempuan lebih baik memusatkan perhatian dan enerji demi kesembuhan dari depresi yang diderita dengan beristirahat total daripada menghabiskan enerji untuk menulis. Hal ini bertentangan dengan pemikiran istri: "I sometimes fancy that in my condition if I had less opposition and more society and stimulus-but John says the very worst thing I can do is to think about my condition, and I confess it always makes me feel bad" (Gilman, 1977: 44).

Keterpenjaraan dalam bentuk opresi psikis dan emosional juga terjadi ketika tokoh perempuan dianggap mengada-ada tentang wallpaper. Tokoh perempuan merasa tidak nyaman dengan wallpaper di ruang tidurnya dan mengusulkan untuk mengganti: "He said that after the wallpaper was changed it would be the heavy bedstead, and then the barred windows, and then that gate at the head of the stairs, and so on" (Gilman, 1977: 47). Suami sama sekali tidak menganggap penting perasaan istri.

Lebih lanjut, suami memanggil istri dengan panggilan-panggilan khusus: "called me a blessed little goose" (Gilman, 1977: 47) dan "little girl" (Gilman, 1977: 52). Panggilan-panggilan ini di permukaan memberikan kesan rasa sayang yang besar namun di balik itu sebenarnya mengecilkan keberadaan tokoh perempuan. Tokoh perempuan tidak pernah dianggap sebagai perempuan dewasa yang memiliki pendapat yang layak didengarkan dan dihargai. Oleh karena itu, pemikiran istri bahwa kondisi depresi yang dialaminya akan sangat berkurang jika ia diperbolehkan menulis dan bersosialisasi hanya menjadi pendapat personal yang terperangkap dalam penjara aturan suami yang tak terbantahkan: "I think sometimes that if I were only well enough to write a little it would relieve the press of ideas and rest me ... It is so discouraging not to have any advice and companionship about my work" (Gilman, 1977: 47).

Perhatian berlebihan, ungkapan sayang berlebihan, harapan dan tuntutan berlebihan dari suami semakin mengopresi istri secara psikis: "He said I was his darling and his comfort and all he had, and that I must take care of myself for his sake, and keep well" (Gilman, 1977: 51). Istri mau tidak mau menjadi terpaksa mengikuti aturan suami yang sudah sedemikian sayang padanya selama ini. Dengan 
demikian, meskipun tidak bisa dibuktikan secara empiris, keterpenjaraan psikis yang diwarnai opresi psikis-emosionalintelektual mendominasi kehidupan tokoh perempuan yang didiagnosa mengalami depresi paska melahirkan anak kedua.

\section{USAHA MENGATASI \\ KETERPENJARAAN}

Tokoh perempuan bukannya tidak menyadari bahwa keberadaannya terpasung total dengan "rest cure" yang diterapkan tanpa kompromi oleh suaminya yang seorang dokter terkenal. Ketidaksetujuannya hanya bisa diungkapkan dalam hati tanpa ada seorangpun yang mendengarkan apalagi membelanya: "Personally, I disagree with their ideas. Personally, I believe that congenial work, with excitement and change, would do me good. But what is one to do?" (Gilman, 1977: 44).

Menyadari bahwa tidak ada yang akan menolongnya dari situasi terpenjara di lingkungan rumah tangganya sendiri, tokoh perempuan berusaha mengurangi kondisi keterpenjaraannya tersebut. Ia menulis secara sembunyi-sembunyi untuk mengurangi ketegangan psikis yang dirasakannya: "but this is dead paper and a great relief to my mind" (Gilman, 1977: 44). Tokoh perempuan menganggap bahwa kertas tidak bisa mengadu kepada suaminya sehingga ia merasa bebas dan aman menumpahkan pikirannya.

Usaha lain yang dilakukan tokoh perempuan untuk keluar dari keterpenjaraannya adalah dengan mengusulkan pindah kamar tidur: "I don't like our room a bit. I wanted one downstairs that opened on the piazza and had roses all over the window, and such pretty old-fashioned chintz hangings! But John would not hear of it. He said there was only one window and not room for two beds, and no near room for him if he took another" (Gilman, 1977: 45). Kamar tidurnya yang sekarang di lantai atas dan bekas kamar anak-anak dinilai memposisikannya sebagai sosok yang tidak dewasa dan terpasung. Kamar yang dipilihnya adalah kamar di lantai bawah yang memberikan kesan lebih dewasa dan lebih terbuka, namun usulan ini ditolak mentah-mentah oleh suami. Argumen suami yang berbalut pengetahuan medis dan perhatian besar seorang suami sangat tidak terbantahkan.

Tokoh perempuan juga berupaya menyangkal efektivitas dari perawatan yang diterapkan suami kepadanya: "“'I don't weigh a bit more," said I, "nor as much; and my appetite may be better in the evening when you are here, but it is worse in the morning when you are away!"'" (Gilman, 1977: 52). Ia berusaha menunjukkan bahwa isolasi dalam bentuk "rest cure" tidak membuat kondisinya membaik. Yang ia butuhkan adalah teman sebagai bentuk sosialisasi yang membuatnya merasa nyaman sehingga selera makannya muncul. Namun seperti yang bisa diduga semua upayanya ini terpental membentur tembok patriarki dalam bentuk kekukuhan suami atas kebenaran metode perawatan "rest cure".

Upaya terakhir yang dilakukan istri untuk mengurangi keterpenjaraannya adalah menciptakan ruang tersendiri bagi dirinya untuk bisa aktif, jika tidak secara kongkrit maka secara imajiner. Objek yang sejak awal memancing daya imajinasinya adalah wallpaper di ruang tidurnya. Bagi tokoh perempuan, wallpaper itu menggelitik kepekaannya dari segi warna, motif, bahkan baunya (Gilman, 1977: 5556.) Kesemuanya ini semakin jelas di bawah cahaya bulan ketika malam hari tiba. Namun ia harus melakukannya secara sembunyi-sembunyi agar tidak diketahui suaminya. Kesemuanya ini akan dibahas lebih lanjut pada sub-bab berikutnya. 
HUMANIKA Vol. 21 No. 1 (2015) ISSN 1412-9418

Keterpenjaraan Tokoh Perempuan Dalam Cerpen

The Yellow Wallpaper Karya Charlotte Perkins Gilman

Ratna Asmarani

\section{DAMPAK KETERPENJARAAN}

"Rest cure" yang diterapkan suaminya sebagai cara untuk mengatasi depresi paska melahirkan yang dialami tokoh perempuan menimbulkan dampak yang cukup signifikan, baik secara fisik maupun secara psikis. Tokoh utama menjadi cepat merasa lelah meskipun tidak melakukan pekerjaan fisik yang berat: "I did write for a while in spite of them; but it does exhaust me a good deal-having to be so sly about it. Or else meet with heavy opposition" (Gilman, 1977: 44). Kegiatan menulis yang dilakukan tokoh utama sekarang menimbulkan kelelahan yang luar biasa. Kelelahan ini bukan karena secara fisik menulis memerlukan enerji yang besar, namun kelelahan ini lebih dipicu oleh sebab-sebab yang bersifat non fisik. Kegiatan yang harus dilakukan secara rahasia karena dihantui oleh penentangan dan pelarangan yang tegas berdampak menguras energi tokoh utama. Suasana opresif ini tak terelakkan lagi menguras energi tokoh perempuan.

Dampak non fisik dari suasana keterpenjaraan yang opresif ini adalah emosi tokoh perempuan menjadi tidak stabil. Ia menjadi mudah uring-uringan dan gampang menangis tanpa sebab, namun itupun dilakukannya dengan sembunyisembunyi: "I'm getting dreadfully fretful and querulous. I cry at nothing, and cry most of the time. Of course I don't when John is here, or anybody else, but when I am alone" (Gilman, 1977: 49). Di sini tampak betapa tidak bebasnya tokoh perempuan tersebut bahkan hanya untuk menumpahkan emosinyapun ia harus mencuri-curi kesempatan.

Selain itu, diposisikan tidak mampu menjalankan peran gendernya sebagai istri dan ibu membuat tokoh perempuan tersebut merasa tidak berguna dan menjadi beban bagi suaminya: "It does weigh on me so not to do my duty in any way! I meant to be such a help to John, such a real rest and comfort, and here $I$ am a comparative burden already!" (Gilman, 1977: 46). Di sini tampak bahwa tokoh perempuan merasa kehilangan peran gendernya sebagai ibu rumah tangga yang digantikan pengasuh anak dan saudara perempuan suaminya.

Ketika kegiatan fisik dan sosialisasi kongkrit dilarang, pelarian yang ada hanyalah kegiatan non fisik dan sosialisasi imajiner. Yang memicu kegiatan sosialisasi imajiner adalah keberadaan wallpaper yang melapisi tembok kamar tidur tokoh perempuan. Awalnya tokoh perempuan tergelitik untuk bereaksi terhadap warna wallpaper tersebut: "The color is repellant, almost revolting; a smoldering unclean yellow, strangely faded by the slow-turning sunlight. It is a dull yet lurid orange in some places, a sickly sulphur tint in others. No wonder the children hated it! I should hate it myself if I had to live in this room long" (Gilman, 1977: 46). Bagi tokoh perempuan, warna kuning pada wallpaper sangat menjijikkan dan membuatnya merasa mual. Warna kuning itu kotor, pudar di sana sini, suram, dan membosankan. Tokoh perempuan membenci wallpaper berwarna kuning memuakkan tersebut. Karena wallpaper tersebut sobek di sana-sini, tokoh utama berasumsi bahwa anak-anak yang dulunya menempati ruangan tersebut juga membencinya sehingga menyobeknya di beberapa bagian.

Selain warnanya yang mengerikan, pola gambar pada wallpaper tersebut dalam persepsi tokoh perempuan menimbulkan perasaan tersiksa: "The color is hideous enough, and unreliable enough, and infuriating enough, but the pattern is torturing" (Gilman, 1977: 53). Hal ini dikarenakan pola gambar pada wallpaper tersebut berbentuk sulur-sulur berbunga aneh yang jalin menjalin dengan ruwetnya (Gilman, 1977: 53). Tokoh perempuan merasa pusing dan tidak nyaman setiapkali menatap pola ruwet pada wallpaper tersebut. 
Kedekatan imajiner tanpa kata mulai terbangun antara tokoh perempuan dan wallpaper di dinding kamar tidurnya. Interpretasi terhadap wallpaper menguat saat malam hari: "At night in any kind of light, in twilight, candlelight, lamplight, and worst of all by moonlight, it becomes bars! The outside pattern I mean, and the woman behind it is as plain as can be" (Gilman, 1977: 54). Tokoh perempuan mengidentifikasi sulur-sulur pola wallpaper sebagai jeruji dan nampak sosok perempuan di baliknya. Malam hari adalah kebebasan bagi tokoh perempuan karena dengan tidurnya suami, tidak ada yang mengawasi kegiatan tokoh utama. Secara simbolik malam hari, apalagi dengan adanya bulan dan cahayanya, merujuk pada dunia perempuan yang samar, sembunyisembunyi, dan subversif.

Interpretasi terhadap wallpaper pada siang hari bertolak belakang: "By daylight she is subdued, quiet. I fancy it is the pattern that keeps her still. It is so puzzling. It keeps me quiet by the hour" (Gilman, 1977: 54). Baik sosok perempuan imajiner dalam wallpaper maupun tokoh perempuan menjadi pasif dan tertekan di siang hari. Secara simbolik siang hari merupakan dunia laki-laki yang aktif, agresif, dominan, dan publik yang menindas dan memarjinalkan perempuan.

Dengan adanya kedekatan dengan wallpaper yang sekarang menjadi fokus analisisnya, tokoh perempuan merasakan perubahan yang signifikan dalam kehidupannya yang dulunya diwarnai oleh depresi: "Life is very much more exciting now than it used to be. You see, I have something more to expect, to look forward to, to watch. I really do eat better, and am more quiet than I was" (Gilman, 1977: 54). Kehidupannya lebih bergairah dan tidak monoton lagi karena ia mulai aktif secara intelektual dalam dunia imajiner-kreatif. Inilah yang dari dulu menjadi dunia kehidupan tokoh perempuan yang ditentang keras oleh suaminya.
Menemukan aktivitas yang menghidupkannya di malam hari, tokoh perempuan kemudian mengubah pola hidupnya: "I'm feeling ever so much better! I don't sleep much at night, for it is so interesting to watch the developments; but I sleep a good deal in the daytime. In the daytime it is tiresome and perplexing" (Gilman, 1977: 55). Ia memilih aktif di malam hari, ketika kebebasan berimajinasi berada dalam genggamannya, dan memilih tidur di siang hari. Siang hari adalah hari yang melelahkan karena ia teropresi dengan metode "rest cure" yang mengharuskannya menjadi pasif dan objek yang harus minum serangkaian obat-obatan secara teratur serta diawasi dengan ketat.

Analisis diam-diam namun intensif terhadap wallpaper membuat tokoh perempuan semakin jelas melihat keberadaan sosok imajiner di balik sulursulur tanaman yang menjadi motif wallpaper: "I see her in that long shaded lane, creeping up and down, I see her in those dark grape arbors, creeping all around the garden" (Gilman, 1977: 56). Sosok perempuan imajiner tersebut tidak hanya berdiam diri namun bergerak aktif melakukan aktivitas merangkak di balik sulur-sulur pola wallpaper.

Aktivitas yang dilakukan perempuan imajiner dalam wallpaper menginspirasi tokoh perempuan untuk berani melakukan aktivitas fisik: "I always lock the door when I creep by daylight. I can't do it at night, for I know John would suspect something at once" (Gilman, 1977: 57). Selama menjalani metode "rest cure", aktivitas fisik terlarang bagi tokoh perempuan. Siang hari ada saudara perempuan suami yang melayani dan sekaligus mengawasinya, malam hari ada suaminya yang tidur disampingnya yang tidak memungkinkan baginya melakukan aktivitas fisik apapun tanpa ketahuan. Untuk menyiasati pengawasan ini, tokoh perempuan melakukan kegiatan merangkaknya di siang hari ketika 
HUMANIKA Vol. 21 No. 1 (2015) ISSN 1412-9418

Keterpenjaraan Tokoh Perempuan Dalam Cerpen

The Yellow Wallpaper Karya Charlotte Perkins Gilman

Ratna Asmarani

suaminya bekerja di kota sebagai dokter dan mengunci kamarnya agar saudara perempuan suami tidak mengetahui dan kemudian melaporkan ke suami.

\section{AKHIR DARI \\ KETERPENJARAAN}

Keterpenjaraan yang opresif secara fisik dan psikis atas nama metode "rest cure" ini akhirnya dihentikan oleh tokoh perempuan. Ia yang selama ini menjadi objek perawatan yang pasif memutuskan untuk mengubah posisinya. Ia mengambil alih kendali atas dirinya, atas tubuh dan pikirannya. Realisasi pertama dari kendali atas diri sendiri yang dilakukan tokoh perempuan adalah dengan menjadi penguasa di kamar tidurnya: "I have locked the door and thrown the key down into the front path. I don't want to go out, and I don't want to have anybody come in, till John comes" (Gilman, 1977: 58). Ia sengaja mengunci diri di kamar tidurnya dan membuang kuncinya ke luar jendela. Tokoh perempuan tersebut sekarang menjadi penguasa di kamar tidurnya.

Tindakan kedua adalah merobek habis wallpaper sepanjang dinding kamar: "I pulled and she shook, I shook and she pulled, and before morning we had peeled off yards of that paper" (Gilman, 1977: 58). Ia tidak sendirian dalam aktivitas ini. Perempuan imajiner dalam wallpaper membantunya. Mereka bahu membahu merobek wallpaper sampai habis. Di sini wallpaper menjadi simbol keterpenjaraan. Secara imaginer wallpaper menghalangi sosok perempuan imajiner untuk keluar dan beraktivitas bebas. Bagi tokoh perempuan, wallpaper dan tembok dinding kamarnya, keduanya mengungkung kebebasannya. Wallpaper dengan motif sulur-sulurnya yang bagaikan jeruji besi dan dinding masif tembok kamar merepresentasikan penjara patriarki yang dengan berbagai cara dan berbagai bentuk memenjarakan perempuan. Tokoh perempuan tidak saja terpenjara dalam dunia domestik dengan peran gender yang tidak memberi banyak ruang pada aktivitas intelektual dan daya imajinasi, namun bahkan peran gender inipun diambil darinya ketika ia didiagnose mengidap depresi. Lingkup ruang rumah tanggapun menciut jadi lingkup ruang kamar, aktivitas sebagai istri dan ibu menciut jadi aktivitas sebagai pasien "rest cure" yang harus pasif total.

Keberhasilan merobek habis wallpaper tidak saja memberikan atmosfer kebebasan bagi tokoh perempuan, namun juga menimbulkan keberaniannya untuk melakukan tindakan lebih lanjut: "It is so pleasant to be out in this great room and creep around as I please! ... But here I can creep smoothly on the floor, and my shoulder just fits in that long smooch around the wall, so I cannot lose my way" (Gilman, 1977: 59). Tokoh perempuan tidak peduli lagi atas reaksi pihak lain yang melihatnya merangkak sepanjang dinding kamar tidur. Ini adalah ekspresi kebebasannya sebagai individu. Dari kacamata feminisme, ini adalah simbol langkah awalnya menyiasati tembok patriarki yang mengurung di mana-mana.

Kegiatan merangkak yang dilakukan dengan penuh kepastian oleh tokoh perempuan tidak terhenti meskipun suami akhirnya bisa masuk kamar setelah menemukan kunci atas petunjuk tokoh perempuan: "I kept on creeping just the same, but I looked at him over my shoulder. "I've got out at last," said I, "in spite of you and Jenny. And I've pulled off most of the paper, so you can't put me back!" (Gilman, 1977: 60). Tokoh perempuan mendeklarasikan kebebasannya dengan mantap. Ia merasa telah berhasil mengatasi kungkungan yang direkayasa oleh suaminya dan didukung penuh oleh saudara perempuannya.

Namun reaksi yang dramatis ditunjukkan oleh suami. Suami yang merupakan dokter handal, yang terbiasa menangani kasus-kasus kesehatan yang 
gawat, yang sangat praktis sekaligus patriarkis, mendadak pingsan mengetahui kegiatan istri: "Now why should that man have painted? But he did, and right across my path by the wall, so that I had to creep over him every time!" (Gilman, 1977: 60). Pingsannya suami sama sekali tidak mempengaruhi ativitas merangkak yang dilakukan istri meskipun ia harus merangkak melewati tubuh suami yang menghalangi jalur merangkaknya.

Kejadian ini secara simbolik membalikkan hierarki yang umumnya berlaku. Aktivitas bergerak umumnya merujuk ke laki-laki sedangkan pasivitas seperti keadaan pingsan umumnya dijadikan sifat perempuan. Di sini tokoh perempuan sekali memutuskan untuk bergerak maka terus menerus bergerak, mulai merobek habis wallpaper sampai merangkak sepanjang tembok kamar tanpa henti. Kedatangan suami tidak menghentikan tindakannya. Suami tidak lagi menjadi pemegang otoritas atas dirinya sekali ia berhasil merebut kendali otoritas tersebut. Di sisi lain, suami sebagai sosok yang diharapkan rasional sesuai dengan gender dan profesinya ternyata malah menunjukkan sifat feminin, yaitu pingsan, ketika ia tidak lagi merasa bisa mengontrol istrinya.

Dari kacamata feminis, pingsannya suami ini juga merupakan simbol runtuhnya otoritas laki-laki atas perempuan. Pingsannya suami juga bisa diartikan sebagai ketidaksiapan patriarki menghadapi pemberontakan perempuan. Bisa juga diartikan sebagai kegagalan untuk menjadi pilar rasional yang mengontrol irasionalitas perempuan. Sementara itu, istri yang tetap merangkak sambil melangkahi tubuh pingsan suami dari kacamata feminis merupakan simbol kekukuhan tekad perempuan sekaligus kehati-hatian untuk tidak tergesa-gesa melakukan tindakan lanjutan yang lebih agresif dari sekedar merangkak meskipun satu penghalang sudah tumbang.
Merangkak sendiri dari kacamata feminis bisa diartikan sebagai bentuk langkah awal perempuan untuk mewujudkan eksistensinya sebagai individu yang bebas.

\section{THE YELLOW WALLPAPER SEBAGAI KRITIK PENULISNYA ATAS NASIB PEREMPUAN ABAD SEMBILAN BELAS}

Cerpen The Yellow Wallpaper yang ditulis oleh Charlotte Perkins Gilman merupakan kritik pedas atas metode pengobatan dokter Silas Weir Mitchell yang dinamakan 'rest cure' untuk perempuan yang didiagnose mengidap depresi. Kritik ini berdasarkan pengalaman pribadi Gilman yang pernah menjalani metode pengobatan ini ketika ia mengalami depresi karena merasa terjebak dalam rutinitas kehidupan domestik yang tidak memberinya kesempatan untuk mengaktualisasikan diri. Metode pengobatan ini hampir membuatnya menjadi gila dan ia memutuskan untuk tidak lagi menjalani metode pengobatan ini. Kegiatan menulis yang kemudian ditekuninya menyalurkannya kreativitas dan imajinasinya dan bukan saja menyelamatkannya dari kegilaan namun juga membuatnya menjadi penulis yang produktif dan terkenal (http://www2.webster.edu/ woolflm/gilma n.html diakses tanggal 23 Maret 2014).

Sebagai seorang feminis Gilman prihatin atas depresi yang dialami perempuan abad sembilan belas yang seringkali mengejawantah dalam bentuk stigma kegilaan. Lingkungan patriarkis dan stereotip sifat perempuan abad sembilan belas membuat perempuan semakin terjebak dalam ruang dan peran yang tidak saja membatasi namun juga mematikan kreativitas dan imajinasi perempuan. Melalui cerpen The Yellow Wallpaper tersebut Gilman menunjukkan bahwa kreativitas dan imajinasi perempuan seharusnya diberi ruang dan kesempatan yang layak karena hal itu akan menyelamatkan perempuan dari depresi. 
Gilman sangat mendukung ide bahwa perempuan harus memiliki kegiatan yang tidak hanya terbatasi oleh peran gender yang diharapkan dan diharuskan oleh lingkungan patriarkis. Namun Gilman juga menyadari bahwa tidak mudah bagi perempuan untuk merealisasikannya. Diperlukan keberanian dari pihak perempuan untuk memutuskan nasibnya sendiri. Dukungan dari perempuan lain juga berperanan besar. Sekalipun demikian, kadangkala hanya dalam dunia imajiner perempuan bisa merasakan sedikit kebebasan meskipun untuk itu perempuan menghadapi resiko dianggap 'gila' karena bertingkah laku tidak sesuai dengan harapan masyarakat. Kritik feminis Gilman ini tertuang dengan apik dalam cerpennya yang berjudul The Yellow Wallpaper.

\section{SIMPULAN}

Dari hasil analisis tentang keterpenjaraan tokoh perempuan dalam cerpen The YellowWallpaper karya Charlotte Perkins Gilman dapat disimpulkan sebagai berikut. Tokoh perempuan dengan caranya yang sangat khas mengatasi kondisi keterpenjaraan secara fisik, psikis, emosional, dan intelektual yang dialaminya. Tidak mungkin mendobrak atau keluar dari bentuk keterpenjaraan yang diciptakan suami yang merupakan pilar patriarki, ia memilih menciptakan dunia imajiner dan pindah ke dalamnya. Tidak memiliki teman untuk bersosialisasi di dunia nyata yang patriarkis dan opresif, ia menciptakan teman di dunia imajiner. Dengan kata lain, tokoh perempuan memutuskan untuk hidup dalam dunia imajiner karena sudah tidak memiliki ruang bebas dalam dunia nyata. Di dunia imajiner inilah tokoh perempuan menemukan kebebasannya, yaitu kebebasan beraktivitas sesuai kehendaknya dan kebebasan mengungkapkan pikirannya.

Namun kebebasan sebagai bentuk dari keberhasilan yang dicapai tokoh perempuan ini bersifat temporer dan terbatas. Begitu suami sebagai pilar patriarki yang rasional dan memiliki otoritas terbangun dari keadaan pingsan, ia akan segera merenggut keberhasilan ini. Terbuka kemungkinan tokoh perempuan akan dimasukkan dalam rumah sakit jiwa dan menerima stigma gila dari masyarakat. Kebebasan tokoh perempuan juga bersifat terbatas, yaitu hanya dalam dunia imajiner rekaannya sendiri. Sementara itu, dinding tembok kamar tidur di rumah peristirahatan akan segera berganti dengan dinding tembok di rumah sakit jiwa. Itulah bentuk kebebasan yang dengan susah payah diperjuangkan perempuan karena pada dasarnya, disadari atau tidak, perempuan selalu berada dalam berbagai bentuk pemenjaraan yang dilakukan oleh masyarakat patriarkis.

\section{DAFTAR PUSTAKA}

Beekman, Mary. Charlotte Perkins

Gilman. Her life and works as a social scientist

and feminist

(http://www2.webster.edu/ woolflm/gilma

n.html diakses tanggal

23 Maret 2014).
Behrendt, Stephen C. 2008. Contextual Analysis.

(http://www.unl.edu/english/sbehre ndt/StudyQuestions/ContextualAna lysis.html) accessed February 17, 2014) 
HUMANIKA Vol. 21 No. 1 (2015) ISSN 1412-9418

Keterpenjaraan Tokoh Perempuan Dalam Cerpen

The Yellow Wallpaper Karya Charlotte Perkins Gilman

Ratna Asmarani

Chesler, P. 1972. Women and Madness.

Doubleday: New York.

Gilbert, Sandra M. and Gubar, Susan. 1979. The Madwoman in the Attic. The Woman

Writer and the Nineteenth-Century

Literary Imagination. New Haven and

London: Yale University Press.

Gilman, Charlotte Perkins. 1977. "The

Yellow Wallpaper" in In the Looking

Glass.

Twenty-One Modern Short Stories

by Women. Edited by Nancy Dean \& Myra

Stark. New York: G.P. Putnam's

Sons, pp. 43-60.

Guest Post: The psychological is political:

Mental health as a feminist issue

(http://www.shamelessmag.com/bl

og/2012/08/guest-post-the-psychological-

is-political-mental-/ diakses 1

Januari 2014).

Halliday, Penny. 2005. "What Sort of Mental Health Problems are Experienced by

Women in Contemporary British Society? What do Different Feminist

Perspectives Offer as Alleviation?" in Journal of International Women's

$\begin{array}{lll}\text { Studies, } & 6 & \text { (3), 40-49. }\end{array}$ (http://vc.bridgew.edu/cgi/viewcontent.cgi ?article $=$ 2014).

1516\&context=jiws diakses 2 Jan
Humm, Maggie. 1995. The Dictionary of Feminist Theory. Second edition.

Columbus: Ohio State University Press.

\section{Lian, Koh Li. 2011. Oppression I Mental}

Health.

(http://www.social-

dimension.com/2011/10/understanding-

oppression-in-

mental-health.html diakses 1

Januari 2014).

Oppression. Feminism Definition.

(http://womenshistory.about.com/od/femin ism/a/

2014).

oppression.htm diakses 1 Januari

What is a Rest Cure?

(http://www.wisegeek.com/what-is-a-restcure.htm\#slideshow diakses 5 Januari 2014).

Women and depression through the ages, medical model and feminist theory, Part three (http://louiseelcross.hubpages.com/ hub/Women-and-depressionthrough-the-ages-Part-three diakses 2 Januari 2014).

Women in the Nineteenth

(http://www2.ivcc.edu/gen2002/women_in the

nineteenth_century.htm diakses 5 Januari 2014).

http://www.audioenglish.org/dictionary/im prisonment.htm diakses 5 Januari 2013. 